\title{
Use, Adoption and Rise of Web Media as tools of Communication for Election Campaign in India
}

\author{
Dr. Narasimhamurthy $\mathrm{N}$ \\ Associate Professor Depar.t of Electronic MediaPK Block, Bangalore University \\ Palace Road, Bangalore-5600 09. INDIA
}

\begin{abstract}
The present study is to examining the relationship between web based communication media use, adoption and rise of new media platforms as an tools of communication and political participation, mobilization, engagement, knowledge on voting behavior. In Indian politics web based media started to assume as a central role in mobilizing voters and especially the new generation of young adults. The increases in the use of web media in India are shown as significant and it is essential to do research. In the context of India, research on the cognitive and behavioral effects of media on political participation, use, adoption and rise of new media or social media or web media effects on political participation has been new in nature and also largely neglected. The present study is to give an attention on landscape of new media in India and the impact of web based media on political participation in general and voting behavior in particular. In the $21^{\text {st }}$ century is to witness of Internet revolution, citizens and younger generation started looking at the Internet as an important sources of information and very influencing medium. It began to voicing their opinions through blogs, opinion polls, social networking and websites. The use adoption and rise of web based media forms by new generations and effects are very interesting to study. The present research is to propose to analyze based on diffusion and innovation theory and its effects of political participation. Further the study is to find the effects of web based media use, adoption and its rises in terms of citizen's participation, mobilization and engagement in political process.
\end{abstract}

Key Words: Web Media, Political participation, Indian politics, Diffusion and Innovation theory.

\section{INTRODUCTION}

In the democratic societies the mass media are most common sources for information about election campaigns. The information available to citizens through mass media or any other kind of communication channels about the issues, ideology and policies of the political parties, leaders and candidates, the elections campaigns is very important in political communications. Role and responsibility of the mass media at the times of election is debatable issue for media scholars and academicians. Creating public opinion, effects of intended or unintended, voting behavior and ultimately electoral outcomes are influenced by the mass media is very interesting do research. In traditional elections campaign mass media acts as intermediate between parties leaders, candidates and the citizens. Several studies have found that citizens who more information on parties and candidates through media campaign are more likely to have more knowledge about elections and voting, and more knowledge, better understanding of public affairs issues (Drew and Weaver, 2006;Leshner \& McKean, 1997)). The importance of mass media in contemporary political campaigns has given more concentration and debate (Pinkleton, Hall Jamieson and Waldmann). Mass media is an indispensable avenue for political parties and even the contest candidate to reach large audience. The coverage of electoral campaigns and airing of political advertisements will have the potential of changing the voting decisions of the voters, political advertisement is to the purchase and use of advertising, in very largely to reach and transmit the message of the policies and agenda of the political parties and candidates to mass audience (McNair, 2002). The contemporary political advertisements can be seen as an important means of communication to inform citizens about parties.

The 20th century is witnessed of the convergence of new forms of communication than any other period in history in the field of mass communication. Electricity, the telephone, the automobile, and airplane made the world more accessible to people and transforming our society in the process. As a successive new form of communication have come into being, then the accessible worldwide system of interconnected network called the Internet is publically accessible worldwide, ordinary people have enjoying an expanded quality, range, and choice of entertainment and information content through new communication forms. New forms of communication media play a critical role in building and sustaining, democracies, societies, and economics around the world. New media provide citizens with the information necessary to make informed socio-economic and political choices. These new forms of media give voice to women, youths, and marginalized groups, along 
with their opinions. This new forms communication has more opportunities than the classical mass media. Much of those derives from the new media are a very open and accessible medium. The new medium lays open an incalculable choice of information. Internet has proven to be one of the most dynamic phenomena in modern times. Internet based new forms of communication and information flow has played an important role in the advancement of democratic society. The present research to study the role of this web based information and its effects on electoral process in India.

Election system in India

India is a socialist, secular, democratic republic and largest democracy in the world. The modern Indian nation state came into existence on 15th August 1947. India is a constitutional democracy with a parliamentary system of government, and at the heart of the system lays a commitment to hold regular, free and fair election. These elections determine the composition of the government; the membership of the two houses of parliament, and the state and union territory legislative assemblies. Presidency and Vice-Presidency is the highest body and structure of the system. Conduct of general elections in India for a electing of the people representative involves management of the largest event in the world. The electorate exceeds more than 800 million, voting in approximately more than 800,000 polling station across the nation widely varying geographic and different climate zones, located in snow-clad mountains, the deserts and sparsely populated areas.

The constitution of India has vested, in the election commission, the superintendence, direction and control of the entire process in time to time. For the conduct of elections to parliament and state assemblies and to the office of the president and vice president of India is on very challenging issues in India. The election commission can, justifiably, take pride in having successfully conducted the electoral exercise to the satisfaction of all stake holder and participants, namely political parties and candidates and the electorate. The country's election is involved complex political, mobilization, and organizational logistics that remain unparalleled in globe. An election of India is a contest between different candidates form various parties out of which the voters elect one as their representative. There may also be independent candidates taking part in the election. Delimitation of constituencies, preparation of voters' list, filing of nomination of papers, scrutiny of nomination papers and withdrawals, election campaigns, voting and counting of votes and declaration of result are the procedures of the Indian election system. The elections campaign by various candidates and political parties. Public rallies, posters, pamphlets distribution, processions, door to door campaigns, and using mass media advertisement and more to reach voters.

\section{USAGE OF NEW MEDIA IN INDIA}

Modern India is changing and developing at an incredible pace, the use of information communication technologies for economic development, educational and social change. New information communications technologies and other new media technologies are finding their way deeper into the fabric of Indian life. In the Indian electoral process new media campaigns have become more significant, and are being extensively using by political parties, candidates and citizens to create awareness and garner support. Whilst new media makes it very easier for individuals and organizations to mobilize support on low budget, it is an easy to reach targeted audience in short period or quickly. Political parties, candidates and other institutions and individual who involved in this process in the country are increasingly stated to use web 2.0 tools of communication to reach voters, rise of awareness among the voters in India. Scholars, industry and other political analyzers have argues that the new media has only limited reach, and there is a digital divide with in the country. Further some of them argue and giving examples that of last two United States president elections and extensive use of online media by Barack Obama and his success with comparing the percentage of Internet penetration of both the countries. The last three years Indian Internet penetration is very high compare to United State. But even though parties and candidate are effectively using these online tools to reach supporters, defend the attacks from opponent, and communicate the voters.

New media in India have become increasingly popular components of our younger generation's lives in today's modern society. It provides for new generation to communicate, exchange message, share knowledge, and interact with each other regardless of their distance that separates them. The new media links people across the nation regardless of differences and geographical boundaries. The compression of time and space, the convergence of media and the effects of globalization have made the nation into a more interactive. New generation are feeling more comfortable in use and access of new media for communicating and building relationships through online. The middle age group and adults are very comfortable in use of this technology because they are growing with technological era. The younger generation may not recall how or when they learned to use a computer or access the Internet; for as long as they can remember, those tools were always there. Young people particularly are quick to use the new technology in ways which increasingly blur the 
boundaries' between their online and offline activities. Contemporary media are also developed rapidly as technology changes with new communication technological dimensions and features. The new generations of youths with in the country, who are growing along with new communication technologies are emerging as "new generation."

Asia is the largest growing continent when it to be increased in the use and access of new media users across the world. Compare to other worlds the new media users growing rate is $15 \%$ annually in Asian continent. This is clearly shows that Asian nations role in the growth of the users of new medium. The two major countries, namely China and India are important contributors to this growth with over more than 500 million subscribers. New media use also on the rise globally, and this change is also evident is increased in India, several studies and reports found evidence that more adults use new media, social media and social networks in India than in any other Asian countries. Contemporary media of new media uses in India have become more familiar with the web, its role in providing information has expanded and changed. New media is becoming more and more for new generation's attention, not only for searching for information and communications with friends and family but also for the purposes of involve in political process. This change is taking eyes away from other traditional media. India is at the race with China in use of new media. India has added around $30 \%$ of the people use new media for different purposes in their day-today lives from past two years, and it is growing at the rate of adding 12.5 million Indian users on year to year. Besides the heavy population India stands last when it comes to the average time spent online per visitors, being 12.5 hours. The usage rates are expected to increase as the Internet penetration increases.

New media audience in India is very young compared to the rest of the other nations in the world. Nearly $75 \%$ of new media users in India are under the age of below 35 years and nearly half of them are under 25 years of age. These usage patterns show that the expansion, adaptability and future prospects of the new media in India. Searching information, social networking, e-mail are the top most for the users to use new media in their day-today activities in India. Nearly more than $84 \%$ online audience will use social networks for different purpose of communication and other online activities. It is clearly shows that the young generation is leading the contemporary media revolution in India. The growth and use of new media by younger generation in India for the purpose of their Information and entertainment is leading and going by the current trends.

The report released by Internet and Mobile Association of India the number of Internet users in India is reached 205 million in the year of 2013 end of October it is compared to 137 million in 2012, this increase is shows approximately more than $40 \%$ growth of new media users in India. Several studies cite that by 2014 new media users in India will cross 234 million. This will make India is the second new media consumption base in the word, it is more than Internet users in United States. Rural Indian new media users number also increasing. According to the report, rural India has seen a 58\% growth in terms of active Internet users, from 38 million in2012 to 60 million in 2013

In the context of India, research on the cognitive and behavioral effects of media on political participation, use and effects of new media or social media or web media effects on political participation has been largely neglected. Present study is to focus on landscape of new media in India and the impact of the web media related media on political participation in general and voting behavior in particular. India is a multilingual, multiethnic and multi-religious country with a plethora of factors shaping the contours of political behavior. After liberating from colonial clutches in 1947 the country continues to remain its own parliamentary democracy. However it also has close similarities with American model of federalism. In 2014 Indian electorate size is approximately 800 million, it the world's largest democracy and more than that of European Union and US combined. With all this like United States India has also witnessed the declining levels of political participation of publics and involving in voting. Several researchers have found that the declining levels of civic and political participation can be directly linked to the role played by media (Robert Putnam, 2000). As citizens start spending and use of media, they tend to alienate themselves from civic engagement.

A closer examination of the Indian voting behavior indicates that on overall participation is not high or not low it is in moderate level. After liberation from the colonial clutches the first general was held in during 1952, nearly 61.16 percent of the voting populations have cast their ballots. In 2009 general elections voter turnout was 59.07 percent. The voter turnout figures were slightly more than that of the 2004 figure of 58.07 percent, but it is not a substantial margin, even we have to make an the comparison of in to the 1952's voting population with 2009's voting population, it is on increased. However, it would be interesting to study the effect of media that to especially web oriented media on political participation and voting behavior in the modern ear. 
In India, web oriented media have brought a meaningful changes to public and private spheres of life more quickly than education, industrialization or any other socio-economic factor. Traditional mass media of print, radio, and televisions served as the primary means of political information and mobilization. The government controlled national network began as a 'modest enterprise' since viewers has started to access to one to many channels. In terms of influencing civic and political engagement, its influence was high when it was liberated from government control. The new liberation polices of Indian government have come into force, Indian television network was also deregulated and cable-satellite network emerged for the first time. From its modest beginning with only few channels in1991 Indian audience have started to access to five hundred or more channels and it is open the eyes of Indian.

The deregulation of the television network in the 1990s was accompanied by the Internet revolution. From 1992 to 2014, the number of Internet users grew from none to millions. Today internet has emerged as a new medium for information delivery. The Internet oriented web media holds the promise of enhancing democracy and changing traditional one-way process of political communications (Grossman, 1995). The role of web media of new media in providing information on politics and other happenings in India becomes relevant because since majority of the Indian population is relatively young.

The influence of the web based new media on political participation has been studies extensively in the western countries and especially in United State. The role of the new med in determining the political participation and voting behavior has been studies form different perspectives-use and access of new media, new media as a source of political knowledge, and new media as a platform for political participation. With the onset of the Internet revolution, more and more scholars have studies the new media as a platform for voicing public opinion (Hook, 2011), had identified voter turnout in democratic system. Many scholars saw that the expansion of web based media, community's involvement in online, without any restriction to share views, to make freely the opinions, the generations are born with digital technologies or digital natives, and reach all parts of the world with in a minutes, very quickly reach the targeted audience and more are the peoples involving more and more in political process. New media saw as a medium for all the sections of the society can access. However, some of the others have argues that it is 'near-equal' access to the Internet is established in the future then it will have a strong potential for expanding online political participation (Krueger, 2002)

\section{SIGNIFICANCE OF THE STUDY}

The purposes of conducting this study are in twofold: To explore the access and use of web based media behavior for disseminate political messages to the masses in India, and to analyze the impact of new media on political participation, sentiments generated by the political parties and individual candidates in election process and voting behavior. The second fold of the research is to explore the use of web based media by the citizens and political information sharing in India. The present research is to allow us to understand the role of web based mass medium within the citizen's participation in electoral participation. Further the study is to explore the relationships between sentimental messages, public opinion and use of the new media.

Within the country, 2014 was a significant year. The parliamentary general elections were held in the months of March, April and May. All political parties and candidates have extensively used web based social media and online media to reach targeted voting population through sharing information, policies and future policies and they consider this web based mass medium is an important medium to reach Net generation. The present study is to investigate the role of web based media in relation to citizen' use and access the web based medium for their political information and the flow of political message through new media.

The parliamentary general elections of 2014 shows that the all political parties and candidates have extensively used web 2.0 based election campaigns. It shows that Internet is poised to play a significant role in these elections. With nearly 600 million people have casted their votes to elect their representative. All political parties have tried to wooing the new generation's voters and first time voters of the countries tech-savvy upper middle and middle class. To reach this electorate's, candidates and parties have turned to Web.2.0 based communications such as YouTube, Facebook, Orkut, Podcasts, Live chats, Twitter and online communication tools.

The success and use of web 2.0 campaign in United State presidential election 2008 by Barack Obama is the model for other countries, especially India. Some analysts attribute Obama's victory in large extent to his online campaigns. His own web site helped him to set records in terms of donations and micro level mobilization (Williams and Gulati, 2008). Web campaign has become a legitimate communication channel in the political arena as result of the 2008 Obama's election campaign. Postings cover every imaginable topic 
ranging from political news to product information in a variety of formats, links to website, and direct messages to other users are important campaign strategies which used in online.

\section{THEORETICAL FRAMEWORK OF THE STUDY}

Before empirical research begun, it was believed that the mass media produce direct, immediate and powerful influence on all individual members and audiences. Arguably accumulation theory provides as expiation for the role of the media in changing people attitudes about topics such as information and politics over a period of time. In modern and postmodern society there is a consistent flow of new products, ideas and solutions to providing new interpretation and other kinds of innovations. The range of trivial such as a new hairstyle can be profound such as a new political ideology (DeFleur and Dennis 1994). According to sociologist every innovation is taking up by people in a particular society in a rather regular process which can be described by the diffusion of innovation theory.

The Diffusion of Innovation applies in mass communication in two ways: the innovation of new media products and the role of the media in spreading the innovation of new innovations of ideas, beliefs and fads. First of all media itself is an innovation with each development in media technology, new forms of media and communication are established. These new forms must be adopted by people for the innovation of new innovations is to good examples are the cellular phones and Internet. Today we are adopting the changes brought about by the development of new information communication technologies such as Web 2.0. The theory of diffusion innovation can explain the societal happening in which people adopting the new media for change. Innovation theory is an important component in the field of mass communication, because the media, in modern society are often largely responsible for bringing new items to the attention of people who eventually adopt them.

Diffusion of innovation is " the process by which an innovation is communicated through certain channels over time among the members of a social system (E M Rogers, 1995), further he argues that an innovation can be any 'idea, practice, or object that is perceived as new by an individual or other unit of adoption. The diffusion process includes four key elements of innovation, the social system that the innovation affects, the communication channels of that social system, and time (Rogers, 1995). The notion of innovation in diffusion has also been expanded to include new products, ideas, services, methods and inventions (Chang, 2010). The diffusion innovation provides a strong theoretical background to explain the phenomenon for adoption of innovation of political information seeking and sharing through web based media. The present study is to explore the innovation diffused among users particularly refers to the idea of seeking and sharing political information and opinions through web based media.

To summarize, the study is try to analyze the sharing of information through web based media such as political parties websites, candidates websites, weblogs, social network sites. Several researches have shown that web based media of social media is widely used for political deliberation and that this deliberation reflects the political landscape of electoral population. Although the reference to web based media as an indicator of creating the political opinion to the best of our knowledge, there are no scientific studies systematically investigating the political process through web media. Therefore the aim of the present study is to explore to address the following research questions:

1. Does web based media in India is providing the platform for citizen's to engage actively in electoral process

2. How accurately web media can inform the citizen's in regarding the policies, ideologies of the political parties and candidates

3. In what extent web media serve as a predictor of the election result?

4. How individuals use these new forms of communication in their everyday lives

5. How society is accepting the new innovative media

\section{METHODOLOGY}

The present study is in the nature of qualitative and deep understanding about the particular case, its features and its impact. The richness of the study is to complements of theoretical frame work and answer to research questions. In generally theory is designed to rationally and clearly explain a phenomenon. The basic unit analysis is the use of web based media for sharing information dissemination and active participation of citizens in electoral process. The term relationship deservers same specific attention with regard to the use of web based media in system is viewed as set of elements embedded up active participation of citizen's in political process, and role of new media in mobilizing the mass participation relationship. The present study is focusing methodologically on information flows, issues and actions that in turn to provide a deeper 
understanding of Diffusion Innovation theory. In this research I have tried to analyze the emerging behavior patterns and their participations within the innovation of new information communication technologies and use of these new forms of communications in an electoral process from individuals and community. The study is analyzed the new innovative web based media such as Facebook, twitter, social blogs, search engines, and micro-blogs in disseminating and mobilizing mass for actively participation in electoral process of general assembly elections were held recently in the country. Further the theories of Diffusion of Innovation have been intensively used to explain the aspects and answer to research questions.

\section{DIFFUSION INNOVATION THEORY OF COMMUNICATION}

The theory of diffusion innovation argues that communicators in society with a message influence or encourage people that have strong opinions through the media to influence the masses. The process of adopting new innovation has been studied from many scholars in several ways the one of the most popular adoption models is described by Rogers in his work Diffusion Innovation. For several researches from a broad variety of disciplines has used the model of diffusion of innovation as a framework of political science, public health, communication, history, economics, technology and education. The theory is widely used in the area of the innovation of technology and diffuses of technology adoption. More of the diffusion research involves technological innovations, Rogers argues that 'a technology is a design for instrumental action that reduces the uncertainty in the cause-effect relationships involved in achieving a desired outcome.' Diffusion theory examines the process by which innovation is adopted over time, or by which innovations are communicated through specific channels over time among the members of a social system. According to Rogers there are main diffusion theory has four key elements: innovation, communication channels, time and the social system, innovation is an idea, practice or object perceived to be new by an individual or other unit of adoption. The initial element that sparks diffusion is the invention or introduction of something new into the social system. These invention or introduction needs the members of the social system to adopt it, which involves some form of communication to convince them to reach a mutual understanding to accept change. Since all potential adopters in a social system do not adopt a new product at the same time adopters can be classified into categories, depending on when they adopt the product

Communication is a process in which participants create and share information with one another to reach mutual understanding. It is a kind of social change that involves deliberation and alteration or acceptance of the adopters in the social system. This is so because when new ideas are proposed; they can be diffused and adopted or rejected, leading to certain consequences in the social system. Adoption of ideas can be slow or fast depending on the social values, belief and culture of a society. However, the potential adopters view a change agent effects their willingness to adopt new ideas. Messages are concerned with new ideas and this of course involves some degree of uncertainty and deliberation which sometimes need much convincing, persuasion and time to reach a decision. Another important determinant of the adoption is an innovation is to compatibility with the values, beliefs and past experiences of individual in the social system.

\section{USE, ADOPTION AND RISE OF WEB MEDIA IN INDIA}

Web based application has gained a great popularity in the last twenty years with billions of users across the globe. As a consequence of expansion and diversification of the web based technology application, it becomes a part of individual's daily lives. Today, people are so familiar with the web technology and Internet based applications and new media. Social media and other online communication, which is the final step in the evolution process of the web 2.0 based Internet, can be considered as a greater innovation. It is possible to associate the diffusion and widespread use of new media in the context of decision-making process for innovation.

When this we based media of new media is considered as an innovation, prior conditions like previous practices, individual needs, innovativeness and norms of the social system can also be associated with the usage of new media of communication for the purpose of decision making. The grater expansion of new media and growing chance to experience these new and exciting platforms make people to wonder more about the new media. To get new knowledge, feel good and positive attitude towards innovative idea and object is the result of individual or masses use online or web based media platforms. Within the knowledge stage, in accordance with these prior conditions people met with various web based media platforms.

Indian politics is on the cusp of a revolution led by we based media users. At a very conservative estimate that the Web based media users are shaping the Indian politics. The adoption of these new forms of communication tools is determined by the new media users making them the newest voters. Last several elections the candidates and political parties have extensively used and depended to reach voters is through the use of web based media like social media, such as social networks for campaigns are noticed. It is a serious 
implication, all of it positive, for Indian democracy, for the way it empowers the citizens through web based media and these media technology was adopting by the Indian's. Candidates and political parties have chalk out a well thought out web based media strategy for their campaigns to be very effective.

Mainstream media such as newspaper, radio, television has long played a role in shaping public understanding of and popular attitudes towards political process. In India television even illiterate medium remains an important information source. Citizens of the nation, watching from the sidelines, are turned into spectators. Instead of relying on the mass media, growing number of individuals and groups in India now started to adopt and access information about political events in online. Similar patterns are also highly emerging in western countries. In India people adopting and using web based media communication to stay in touch with political events. Manipulation, wrong information favoritism, negligence to reach unreached population and bias are very much in mainstream Indian media. It is in this context the web based media has become significant, allowing established and aspiring politicians to bypass the traditional mass media their opinion, or to hear directly from public.

The 2014 general parliamentary election is the witness of adoption of new media technology by younger generation and for change. Nearly 3.5 million new youths have been registered till August 2013 as electorates in the capital; this is the increase from .7\% to $2.7 \%$. All political parties say that they cannot ignore youth power during elections. Web based media is an weapon to people for mobilize and action, these mobilize and action through web based media by youths is an example of the last New Delhi election in India, in simultaneously, web based new media will act as catalyst for empowering people on their participation in an electoral process. It is a lesson to all political parties for importance and power of the youths in electoral process. The youths in India ever since they channelized their angst at Anna Hazare anticorruption movement and at India Gate in the aftermath of the 16th December 2013 Delhi gang-rape protest. Their anger was reflected their frustration with the political system and political class. Hence, their votes would be decisive in each assembly constituency.

The media is very essential to democracy and a democratic election is impossible without media. A free and fair election is not only about the freedom to vote and the knowledge of how to cast a vote, but also about a participatory process where voters engage in public debate and share adequate information about the parties, policies and the candidates. The participatory process is very effective in web based media system; here is how the peoples can adopt new technologies to diffuse the information on candidates and political party's ideologies. The participation through web based media and adoption of new technologies by individual or mass is act as crucial change agents in electoral system. The web media has proven to be one of the most dynamic phenomena of our times, its effects on political system.

\section{DEPENDENCY OF WEB MEDIA IN INDIA}

The adoption and dependency of web media into daily lives is reflected in the kinds of activities of Indian web community. It was an estimated of 235 million Internet users across the country at the end of Feb 2014 it indicate that the rise of web based media in India. Several studies have found that Internet had improved their connection with family, friends and others, the way they pursue hobbies, and their ability to learn new things, to share new information, and to get in touch with many people to reach target purpose. Media dependency and use have suggested that the factors such as assessment of needs fulfillment, appropriateness, social norms and peer evaluation are important in determining the nature of media dependency and use (Flanagin and Metzger, 2001). The Media Dependency perspective one might argue that individual goals and the web based media's ability to meet them and it may be exert the influence on others in online environment.

Among many promises and expectation was broken during the course of 2014 parliamentary general assembly election. This was the first true web based media campaign, effects of web media on political process, and the power of digital natives. This election illustrates just the impact of web based media had on the election, and particularly how the younger electorate may have influence the outcome. BJP Party poised as a game-changer are also tapping into the web media in a big way. The party has learnt that from the past election of United state President Barack Obama's campaign strategy effectively to reach out the new voters and digital natives.

All political parties and candidates have extensively used web media in race with BJP Party, but the strategies were different. Obama campaign used web media to create a large volunteer base and reach out every person to get the vote out, but in the context of India BJP well planned to convert its support base into votes. It is team work and to reach the new voters they depended on web based media. The success of BJP is largely depending on Internet or web based media to reach out the target electoral. In India around 65 percent total voting population is 18-35 years of age. Youth votes are those who fall in the age group of 18-35. This means 
that 378 million or more out of a total 814.5 million people eligible to vote in 2014 general elections. Many scholars who believe that this is a huge number and youth always are a crucial target for the success of any political party in India. Nearly 51 percent of male voters and 49 percent female voters are in younger generation. More than 46 percent youth voters are from urban centers and well-connected with web media.

All political parties in India are relying to depending on more and more web based media to attract new generation of young voters, it shows it clear that parties and candidates trying to depend and ride digital wave by conducting workshops to teach leaders and foot soldiers how to improve engagement on websites on web media such as social networks and social media. The country of 1.25 billion people and 814.5 million voters and had 234million Internet users as of Feb 2014 and use and rise of web based media grow about 80 million or more by end-of Feb 2014. It is clear to shows that all political parties the web media is helping as an 'accelerator' in conveying their messages to the public. The web media of Facebook, Twitter, Google, and other most rated social networks have emerged as major players in the last $16^{\text {th }}$ Lokasabha general elections in India. Political parties and candidates have started competing with each other in breaking the news, spreading their message through these outlets in a addition to those via the traditional media.

Use and adoption of web based media is shows that the one of the major and important social network of Facebook alone has more than 100 million users in India itself. Another social network of Twitter has also followed by Facebook. In 2009, among Indian politicians SashiTharoor was the only politician was having a Twitter account and he had 6000 followers, Tharoor is now the second most popular politician on Twitter with 2.16 million followers after Prime Minister NarendraModi with more than 3.89 million followers and nearly 14 million fans of Facebook. The Internet usage in India gradually increasing and most of them are young and mobile urban dwellers. This demographic is also socially engaged, making for the highest Twitter and Facebook usage in world, outside of the United States. These numbers might indicates that the dependency and rise of Internet usage and justify the social push by political parties as a persuasion tool.

The parliamentary general election of 2014 has witnessed web media is a new election battleground for all political parties that to especially BJP. In February, Modi appeared on a giant screen across tea stalls in the country, with a beloved Indian staple in his hand-a cup of tea. This was BJPs discussion over tea campaign, where satellite and mobile technologies were used to host live interaction with people that too youths. This is shows that the flood of online political campaigning, the BJPs strategy has been effective and very attractive persuasion tools of communication. Political parties have engaged experts and given them full liberty to manage their web based media for campaigns, promotions and to create conversations.

\section{CONCLUSIONS}

India is a multilingual, multiethnic, multicultural and multi-religious country with pluralistic character and plethora of factors shaping the contours of political behavior. After the independence from colonial clutches the country continues to remain a parliamentary democracy. In 2014, the size of the Indian electorate is 814.5 million, showing it the world's largest democracy. But like other democratic countries comparison India has witnessed the levels of political participation is low. The present study is analyses the use, depend and rise of web based communication media as a medium of political campaign in 2014 general election of India. Mass media is a major social and political force in our today's world because some of the basic organizing principles and procedures for social and political activities are influenced by these media. In all the ages there will be a one dominant medium in $21^{\text {st }}$ century dominant medium is new media or web based media. All social and political and economic activities occur in and through a medium.

The rise of web media and information communication technologies have that promote the immediacy of communication and information gathering. Changes in the universe of new, information and communication have exerted on impact on how traditional new outlets cover news, how citizens participate politically, how political parties and candidates campaign. The change in new communication technologies occurs so quickly. These changes have to be examine the transformative effects and adoption of web media use and rises on political campaign. This use and rises of web media sources and tools have provided citizens with more and more opportunities to express and organize themselves around their political participation. The web media is now mainstay of political news and communication dependency among Indian young generation to understand the structure of contemporary news choices to them. Web media has become a core element of modern political campaigns. The dependency of communication technologies such as e-mail, websites and podcasts for various forms of communicative tools deliver a message to a large audience. Use and adoption of web media for fundraising, lobbying, volunteering, community building and organizing campaign is become important communication tools in India. Candidates and political parties have use and adopt web media to promote their election campaign. 
Signifying the importance of web media for political campaigning in $16^{\text {th }}$ parliament general election political parties and candidates have relied heavily on web media such as social media and social networks to engage voters, recruit campaign volunteers and raise some extent campaign funds also. The campaign brought the spotlight on the importance of using web media in new-age political campaigning by utilizing various forms of social media and new media to reach new target population. This web media was incredibly successful a reaching the younger population while helping all population to organize and promote action. The last parliament general election is the witness of the effect of web media use and adoption and effects.

\section{REFERENCES:}

[1] Arts, K and Semetko, H.A(2003) 'The divided electorate: Media use and political involvement', Journal of Politics 65:759-784.

[2] Althaus, Scott L., and David Tewksbury(2000) Patterns of Internet Traditional News Media use in Networked Community. Political Comunication 17(1):21-45.

[3] Alverez M R and Hall T E(2004) Click and Vote: The future of Internet Voting. Washington D.C Booking Institution Press.

[4] Bauernschuster, S., O. Flack and L.Woessmann (2011) Surfing Alone? The Internet and Social Capital: Evidence from an Unforeseeable Technological Mistake, IZA Discussion Paper 5747.

[5] Besley. T and R Burgess (2002)The Political Economy of Government Responsiveness Theory and Evidence from India, Quarterly Journal of Economics 117(4) 1414-1451.

[6] Boczkowski, Pablo (2004) Digitizing the News: Innovation in Online Newspapers. Boston MIT Press.

[7] Chang. H C (2010)A new Perspective on Twitter Hashtag Use: Diffusion of Innovation Theory. Paper presented at the Proceedings of the American Society for Information Science and Technology, Pittsburgh Pennsylvania.

[8] Della Vigna, and E Kaplan (2007) The Fox News Effect: Media Bias and Voting, Quarterly Journal of Economics 122(3) 11871234.

[9] DelliCarpini, Michael and Scoot Keeter: The Internet and Informed Citizenry In The Civic Web: Online Politics and Democratic Values, edited by D. Anderson and M. Cornfield. New York :Rowman and Littlefield.

[10] DeFleur, ML and Ball-Rokeach S.J (1989) Theories of mass communication (5 $\left.5^{\text {th }} \mathrm{ed}\right)$ New York: Longman.

[11] Drew, D and D.H Weaver (2006) Voter Learning and Interest in the 2004 Presidential Election:Did the Media Matter? Journalism and Mass Communication Quarterly 83(1) 25-53.

[12] Flanagin A.J and Metzger M .J, 2001 Internet Use in the Contemporary Media Environment, University of California

[13] Grossman, L 2009 Iran Protest: Twitter, the Medium of the Movement, Time, Retrieved from http:/www.time.com/time/world/article/0,8599,1905125,00 html

[14] Hall Jamieson and Waldmann, Paul (2004) The Press Effect: Politicians, Journalists, and the stories that shape the political world. New York:Oxford University Press.

[15] Howard, Philip N (2005)Deep Democracy, Thin Citizenship: The Impact of Digital Media in Political Campaign Strategy, Annals of the American Academy of Political and Social Science 597(1)153-170.

[16] Howard, Philip N (2005) New Media Campaigns and Political Culture. Cambridge, UK Cambridge University Press.

[17] Leshner G and McKean M (1997) Using TV news for Political information during an off-year election: Effects on Political Knowledge and Cynicism. Journalism and Mass Communication Quarterly, 74(1) 69-83.

[18] McNair (2002)An Introduction to Political Communication: New York Routledge,

[19] Pinkleton, Bruce E, Weintraub Austin, Erica and FortmanKrinstine K J (1998) Relationship of Media use and Political Disaffection to Political Efficacy and Voting Behavor. Journal of Broadcasting and Electronic Media 42(1) 34-49.

[20] Rainie, Lee, Michael Cornfield and JhonHorrigan (2005) The Internet and Campaign 2004. Washington,DC: Pew Internet and American Life Project.

[21] Rice, Ronald and James Katz (2004)The Interest and Political Involvement in 1996 and 2000. In Society Online: The Internet in Context, edited by P.N.Howard and S Jones. Thousand Oaks:Sage.

[22] Riker, William H and Peter C Ordeshook (1968) "A theory of the Calculus of Voting" American Political Science Review 62(1) 25-42.

[23] Robert Putnam (2000) Bowling alone: The collapse and revival of American Community. New York: Simon and Schuster.

[24] Rogers, E.M (1995) Diffusion of Innovations (4thed), New York: Free Press.

[25] Stromer-Galley, Jennifer (2004) Will Internet Voting Increase Turnout? An Analysis of Vote Preference. In Society Online: The Internet in Context, edited by P.N.Howard and S Jones. Thousand Oaks:Sage.

[26] Williams, C and Gulati G (2008)What is a social Network Worth? Facebook and Vote Sharein the 2008 Presidential Primaries. In Annual Meeting of the American Political Science Association, 1-17. Boston. 